\title{
Modelling a Collaborative Network in the Agri-Food Sector Using ARCON Framework: The PROVE Case Study
}

\author{
Patricia Macedo ${ }^{1,3}$, António Abreu ${ }^{1,3}$, and Luis M. Camarinha-Matos ${ }^{3}$ \\ ${ }^{1}$ EST Setúbal, Instituto Politécnico de Setúbal, Setúbal, Portugal \\ ${ }^{2}$ ISEL, Instituto Politécnico de Lisboa, Lisboa, Portugal \\ ${ }^{3}$ CTS - Uninova and Faculdade de Ciências e Tecnologia, Universidade Nova de Lisboa, \\ 2829-516 Caparica, Portugal \\ patricia.macedo@estsetubal.ips.pt, ajfa@dem.isel.ipl.pt, \\ cam@uninova.pt
}

\begin{abstract}
PROVE network is an agri-food network that aims to enable small farmers to sell their goods directly to consumers resulting from this exchange benefits to both parties. This network was selected to apply the ARCON Modelling Framework in order to evaluate its appropriateness to represent this kind of collaborative networks. Starting with a brief presentation of PROVE, this paper presents a systematic representation of the network using the ARCON framework. Furthermore a discussion about the benefits, challenges and difficulties found in our experience of applying ARCON to this kind of network is presented.
\end{abstract}

Keywords: Collaborative Networks, modelling framework, ARCON, agriculture sector, case study.

\section{$1 \quad$ Introduction}

In the last decade, the increasing globalization of markets has caused profound changes in global economy. Collaborative networks appeared as a way to face some of the challenges introduced by globalization. There are high expectations that collaborative networks bring clear benefits to its members (Abreu and CamarinhaMatos 2010), (Abreu, Macedo et al. 2008). These benefits include an increase of the "survival capability" in a context of market turbulence, but also the possibility to better achieve common or compatible goals. On the basis of these expectations are, among others, the following factors: joining of complementary skills and capacities, access to new / wider markets and new knowledge, etc. However, in spite of these positive expectations, it is also frequently mentioned that there is a lack of published cases that clearly shows the benefits of such organizational form, which is an obstacle for a wider acceptance of this paradigm. Therefore, this work intends to present a real collaborative network and analyze its characteristics. This case study is based on a Portuguese network in the agri-food sector, the PROVE initiative. This network can 
be framed in the scope of the alternative agri-food networks (AAFN) (Volpentesta and Ammirato 2010), and its aim is to support the development of collaborative processes enabling small farmers to sell their goods directly to consumers, and it already supported the creation of several local networks in distinct regions of Portugal.

Most of the published collaborative networks cases (Ferreira 2001; Garita 2004; Botarelli, Taticchi et al. 2008; Volpentesta and Ammirato 2008) do not follow any specific structure, what implies that: (i) some relevant aspects of networks are not explicitly identified; (ii) for the reader it is more difficult to observe a specific characteristic in the network description; (iii) it is harder to comparatively analyze two networks. In order to overcome these difficulties, the ARCON (Afsarmanesh and Camarinha-Matos 2008) modelling framework, which has been proposed to capture the various aspects involving the representation of Collaborative Networks, is adopted in this case study. There are already a few published cases of modelling collaborative networks using ARCON, such as (Beckett and Jones ; Baldo and Rabelo 2009), and all these cases suggest that ARCON is a useful modelling tool to guide the process of describing and analysing the studied collaborative networks.

The aim of this paper is to present a case study of a specific Portuguese collaborative network in the alternative agri-food sector and to discuss the appropriateness of the ARCON modelling framework to represent this kind of collaborative networks.

\section{ARCON Overview}

ARCON (Afsarmanesh and Camarinha-Matos 2008) is a modelling framework that addresses the complexity involving the representation of CNs. The modelling framework divides this complexity into three dimensions in order to cover all relevant aspects of the Collaborative Networks (CNs) in terms of life-cycle stages, environment characteristics, and modelling intent.

Vertical dimension: Life-cycle stages - This perspective captures the diversity and evolution of CNs during their entire life cycle.

Horizontal dimension: $\mathrm{CN}$ environment characteristics - This perspective includes two subspaces: the internal or endogenous characteristics as well as the external or exogenous interactions that are related to the logical surrounding of the $\mathrm{CN}$ :

- Endogenous Elements subspace represents the $\mathrm{CN}$ from the inside, four subdimensions are proposed: (i) the structural dimension; (ii) the componential dimension; (iii) the functional dimension; and (iv) the behavioural dimension

- Exogenous Interactions subspace represents the $\mathrm{CN}$ as seen from the outside, with a focus on the interactions between the $\mathrm{CN}$ and this environment; four subdimensions are defined: (i) the market dimension; (ii) the support dimension; (iii) the societal dimension; and (iv) the constituency dimension.

Diagonal dimension: Modelling intent - This perspective is related to different intents for the modelling of CNs. Three layers are considered: (i) The general representation 
layer that includes the most general concepts and related relations, common to all CNs regardless of the application domain; (ii) The specific modelling layer that includes more detailed models focused on different classes of CNs; and (iii) the implementation modelling layer that includes models of specific CNs.

\section{The PROVE Network Case Study}

In the last decade, the increasing globalization of markets has caused profound changes in the local farming (Feenstra 1997). The advances in the means of transport and communication, and the improvement of quality of life were the main causes of these changes. As a result, there was a greater exchange of goods and services, which allow access to almost all agricultural products. Nowadays, indeed, we easily find for sale any kind of fruits and vegetables, regardless of the month of the year or the place where we are. Consequently, the result of these changes brings a devastating effect for small local farmers, who do not have access to the market due to their lack of competitiveness in terms of market prices and accessing to distribution channels (O'Hara and Stagl 2001). This environment leads to abandonment of rural activity and in consequence the farming land. As a consequence, the region loses products and services essential to its sustainability and social and economic regeneration, creating serious imbalances in terms of population and regional resources. In order to ensure the sustainability and/or increase the "survival capability" of the region, it is necessary to stimulate farmers, entrepreneurs and service providers for new business models and ways of working (Higgins, Dibden et al. 2008). In this context, the development of collaborative processes that enable small farmers to sell their goods directly to consumers resulting from this exchange a benefit to both parties was the strategic approach that motivated the PROVE network (PROVE 2012).

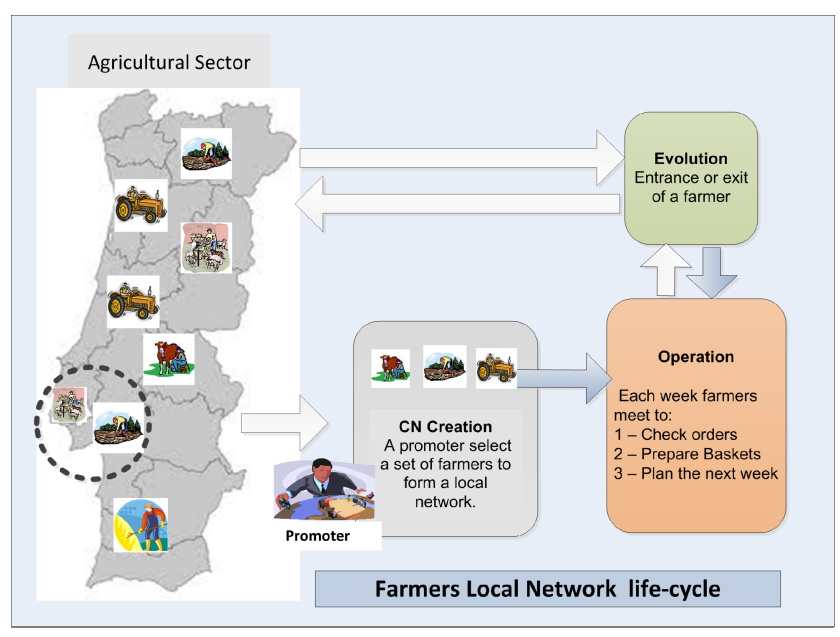

Fig. 1. Farmers Network life-cycle 
The PROVE network initiative can be classified as being an alternative agri-food network where the business model adopted is the direct-sale based on box-schema (Bosona, Gebresenbet et al. 2011). Its main purpose is to increase the negotiation power of farmers with local actors involved directly or indirectly in the business activities of the small farmers, stimulating and reinforcing local business capability of these farmers and promoting the development of a close relationship between farmers and consumers The PROVE initiative is nowadays implemented in the following regions: Sesimbra, Palmela, Lousada, Penafiel, Paços de Ferreira, Montemor-o-Novo, and Mafra. In order to support management activities and ensure the sustainability of the network some ICT tools were developed and several rules related to governance and polices were defined. Fig. 1 shows the life-cycle of a PROVE local network. At the creation phase the local promoter select a set of farmers (such as 3 to 5 farmer) and creates a PROVE network in the target region. During the operation phase, the farmers meet weakly and plan product baskets according to customers' orders and products' season. On the delivery day, the farmers prepare the baskets and make their distribution in the selected locations. In the following week the farmers meet to divide the money from the previous week and start again the process of organizing baskets. However, during the operation phase, new farmers can join the network, and others may go out.

\section{Modelling PROVE Using the ARCON Framework}

In this section, ARCON is used in order to characterize and understand in a systematic way the main dimensions of the PROVE network. Fig. 2 shows the main perspectives of the ARCON framework, which are described below in tables. Following ARCON framework the proposed model belongs to the Specific Modelling Layer, since this layer includes detailed models focused on specific classes of CNs.

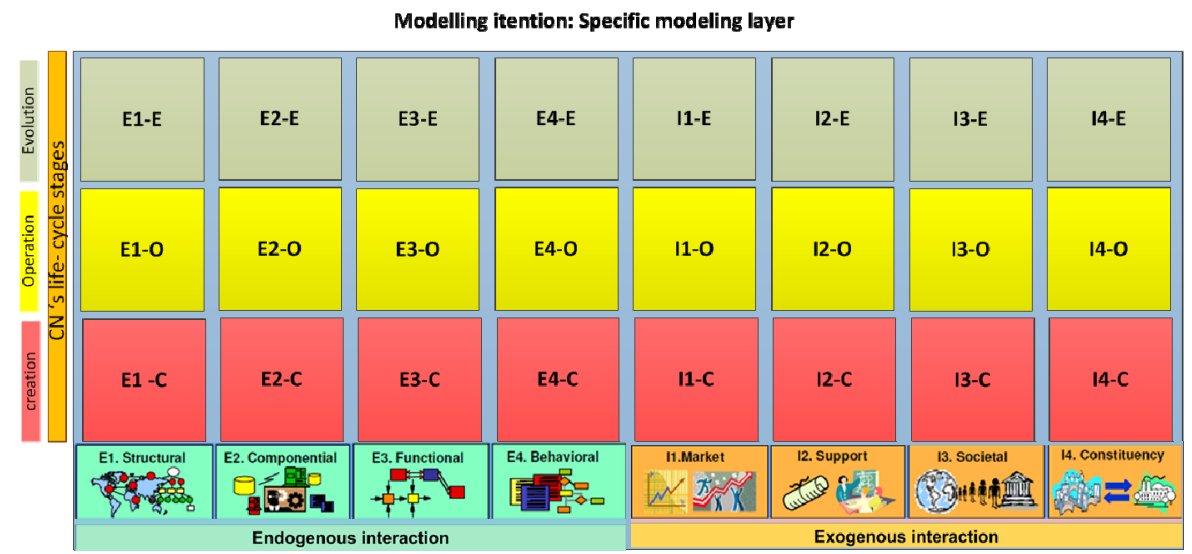

Fig. 2. ARCON Framework 
The Endogenous Elements subspace represents the PROVE network as seen from the inside, in which four sub-dimensions are defined: (i) Structural Dimension, which addresses the structure or composition of the PROVE network constituting elements, as well as the roles performed by those elements; (ii) Componential Dimension, which focuses on the individual tangible/intangible elements of the PROVE network; (iii) Functional Dimension, which addresses the "basic functions / operations" available in the PROVE network; (iv) Behavioural Dimension, which addresses the principles, policies, and governance rules that drive or constrain the behaviour of the PROVE network and its members over time. Table 1 presents a short description of the elements identified as belonging to the ARCON's Endogenous subspace.

Table 1. Endogenous Elements subspace for the PROVE network

\begin{tabular}{|c|c|c|}
\hline \multicolumn{3}{|r|}{ Endogenous Elements subspace } \\
\hline \multirow{3}{*}{ 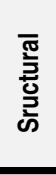 } & C & (i) Promoters; (ii) Facilitator; and (iii) Farmers. \\
\hline & 0 & (i) Facilitator; and (ii) Farmers. \\
\hline & E & $\begin{array}{l}\text { (i) Facilitator; and (ii) Farmers (members of the network and new members who } \\
\text { join the network). }\end{array}$ \\
\hline \multirow{3}{*}{ 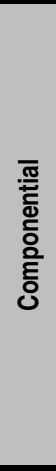 } & c & $\begin{array}{l}\text { Network Components: (i) Human Resources: Individuals that belongs to the } \\
\text { Promoter Organization. (ii) Knowledge: Manual of best practices to manage } \\
\text { PROVE networks. }\end{array}$ \\
\hline & 0 & $\begin{array}{l}\text { Network Components: (i) Human Resources: Individuals that belongs to the } \\
\text { Promoter's organization, Facilitators and Farmers that belong to the network. (ii) } \\
\text { Knowledge: Manual of best practices to manage PROVE networks. (iii) } \\
\text { Technology: G-PROVE software (supports operation). }\end{array}$ \\
\hline & E & $\begin{array}{l}\text { Network Components: (i) Human Resources: Individuals that belong to the } \\
\text { Promoter's organization, Facilitator, Farmers that belong to the network and also } \\
\text { potential new members (Farmers). (ii) Knowledge: Manual of best practices to } \\
\text { manage PROVE networks. }\end{array}$ \\
\hline 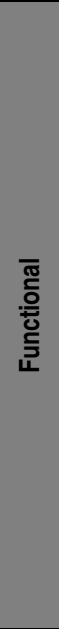 & C & $\begin{array}{l}\text { (i) Preparatory planning phase, which includes the visit of the promoter to } \\
\text { potential farmers and their farming land in order to identify and characterized the } \\
\text { region in terms of: (i) type of available goods, (ii) type of production. } \\
\text { (ii) Consortium formation phase, which includes: (i) farmers and mediators } \\
\text { searching; (ii) promoting meetings in order to explain the business idea to the } \\
\text { potential partners; (iii) farmers and mediators selection to form the network. } \\
\text { (iii) CN Lauching phase, which comprises the specification of the logistic } \\
\text { process, comprising three main activities: (i) defining the workflow to compose the } \\
\text { baskets with fresh vegetables and fruits and assignment of responsibilities (ii) } \\
\text { choosing what of type of basket will be used; and (iii) defining the rules to divide } \\
\text { the profits and to contribute to the common expenses. } \\
\text { (iv) CN set up phase, which includes: (i) customization of the G-PROVE software } \\
\text { system to support the network; (ii) acquisition of the first set of empty baskets to } \\
\text { prepare the first orders; (iii) implementation by the promoter of some marketing } \\
\text { actions in the respective region. }\end{array}$ \\
\hline
\end{tabular}




\section{Table 1. (Continued)}

\begin{tabular}{|c|c|c|}
\hline & 0 & $\begin{array}{l}\text { (i) Operational functions, which are the responsibility of farmers and are related } \\
\text { to farming activities. } \\
\text { (ii) Process orders functions, which are the responsibility of farmers and are } \\
\text { performed weekly and include calculating the quantities of each product per basket } \\
\text { and per farmer, based on the fruits and vegetables available for this week and the } \\
\text { existing orders. } \\
\text { (iii)Accounting functions, which include: (i) setting of the basket price and } \\
\text { products price; (ii) purchasing new baskets; and (iii) dividing the money according } \\
\text { to the agreed norms. } \\
\text { (iv) Control Activities functions, which are the responsibility of the } \\
\text { Facilitator/Promoter, and include the organization of periodic meetings that serve } \\
\text { to monitor the marketing process and to be aware of the main Farmers difficulties. }\end{array}$ \\
\hline & E & $\begin{array}{l}\text { The functions that belong to this phase are: (i) integrating new farmers (each new } \\
\text { farmer accompanies all the operational activities for a certain period, just as an } \\
\text { observer); (ii) re-planning the logistics weekly; (iii) updating the list of available } \\
\text { vegetables and fruits to the consumer. }\end{array}$ \\
\hline & & Endogenous Elements (Endo-E) subspace \\
\hline & C & $\begin{array}{l}\text { The policies and governance rules that drive this phase are: } \\
\text { - The Facilitators and Promoters should be aware of the region's opportunities } \\
\text { and challenges. } \\
\text { - The Facilitators and Promoters should have complementary professional } \\
\text { competences. } \\
\text { - Facilitators should have competences in the area of promoting the relationship } \\
\text { between consumers and farmers. }\end{array}$ \\
\hline & 0 & $\begin{array}{l}\text { 1. Legal and Fiscal Duties of Farmers: } \\
\text { - Each farmer has to contribute with vegetable products from its farm whenever } \\
\text { possible. } \\
\text { - The Farmers have to use sustainable production practices. } \\
\text { - Each Farmer has to coordinate its production with the others Farmers in order to } \\
\text { guarantee variety of products to consumers. } \\
\text { - The elaboration of the basket should follow hygienic principles, and all the } \\
\text { products must be fresh. } \\
\text { - The Farmers should comply with the local and time agreed to deliver the } \\
\text { baskets. } \\
\text { - Each Farmer should improve the landscape of its farm and should encourage } \\
\text { visits from consumers. } \\
\text { - Each Farmer contributes actively to the work group, and participates in } \\
\text { promoting activities. } \\
\text { 2. Legal and Fiscal Duties of consumers: } \\
\text { - The consumer buys the basket previously ordered, accepting that the products } \\
\text { available are seasonal. } \\
\text { - The consumer should respect the local and time agreed for the delivery. }\end{array}$ \\
\hline
\end{tabular}




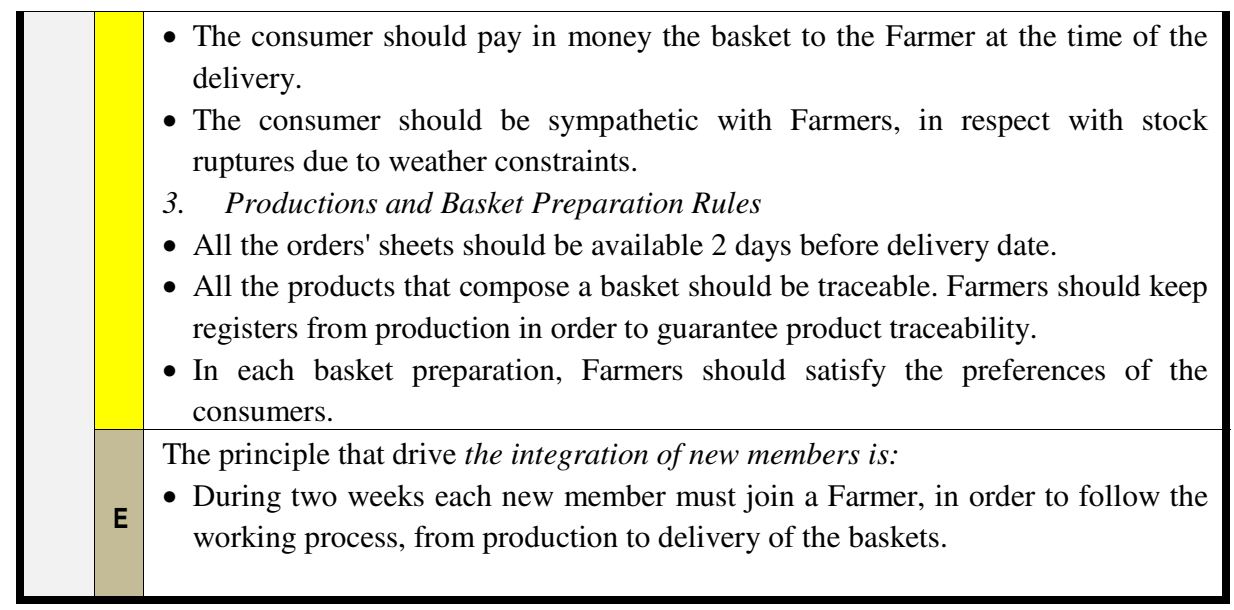

According to the ARCON model the Exogenous Interactions subspace represents the PROVE network as seen in interaction with the outside, with a focus on the interactions between the PROVE network and its environment. Four sub-dimensions are defined: (i) Market Dimension, which covers the issues related to interactions with "customers" and "competitors"; (ii) Support Dimension, which covers the issues related to support services provided by third party institutions; (iii) Societal Dimension, which covers the issues related to interactions between the PROVE network and the society; (iv) Constituency Dimension, which focuses on the interaction with the universe of potential new members of the PROVE Network. Table 2 presents a short description of the elements identified as belonging to the ARCON's exogenous subspace.

Table 2. Summary of Exogenous Interaction subspace for the PROVE network

\begin{tabular}{|l|l|l|}
\hline \multicolumn{1}{|c|}{ Exogenous Elements (Endo-E) subspace } \\
\hline \multirow{2}{*}{$\mathbf{C}$} & $\begin{array}{l}\text { Communication strategy to customers: } \\
\text { (i) The PROVE network is represented by a logo } \\
\text { (ii) A web page which describes the process guidelines. } \\
\text { (iii) An attractive leaflet to reach the customers not covered by the Internet. } \\
\text { (iv) Advertising campaigns in newspapers and local radio stations. }\end{array}$ \\
\hline \multirow{2}{\mathbf{\Phi}}{$\begin{array}{l}\text { Interaction with "customers" and stakeholders: } \\
\text { (i) A web page that supports a FAQ (Frequently Asked Question) service to } \\
\text { consumers. } \\
\text { (ii) Meetings between Farmers and consumers. } \\
\text { (iii) Weekly newsletter. } \\
\text { (iv) Demonstration activities in schools. }\end{array}$} & $\begin{array}{l}\text { Interactions related to admission of new members into the network: } \\
\text { (i) Carry out a visit to the farming land of the potential new member with the } \\
\text { purpose of establishing an exploratory contact. } \\
\text { (ii) General meeting between the potential new member and all other members in } \\
\text { order to identify common interests. }\end{array}$ \\
\hline
\end{tabular}


Table 2. (Continued)

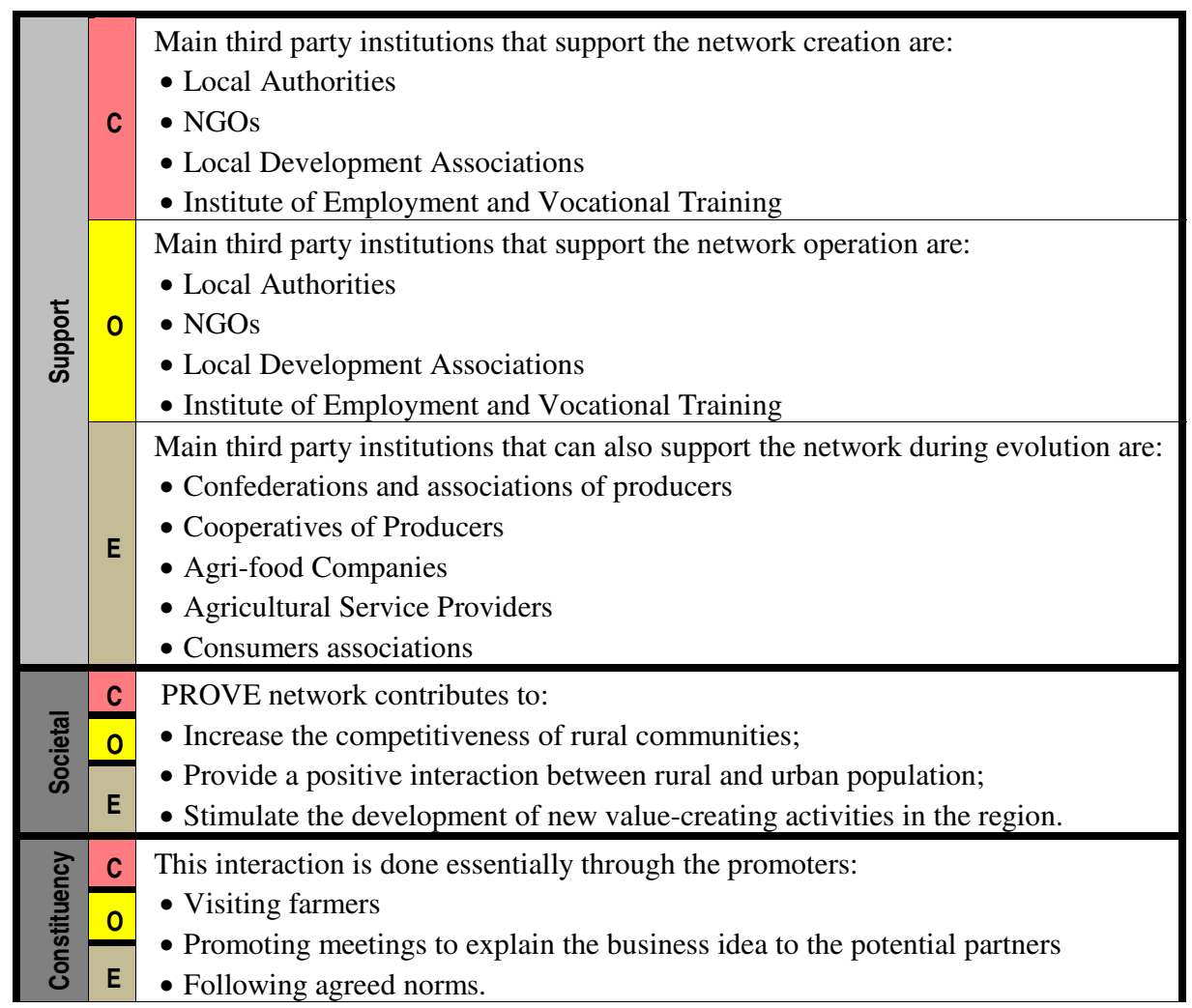

\section{ARCON Application Assessment}

One of the goals of this study is to discuss the advantages of using ARCON as a modeling framework to describe a $\mathrm{CN}$ with the characteristics of PROVE.

PROVE is a network with a low level of complexity and involves a low number of members. In spite of this fact, the use of ARCON, allows us to structure in a systematic way an amount of disperse and unstructured information, and to identify some hidden gaps. Fig. 3 illustrates the mapping in the ARCON framework of the gaps described below.

A1. The use of ARCON allowed to notice that the dissolution phase is not covered. All the formal documents provided by the PROVE network do not cover any item related to the process of disintegration of a PROVE local network. For instance it is not defined: (i) how to manage the cessation of baskets supply; (ii) how to manage the tangible (baskets, vehicles, etc.) and intangible (consumer contacts, consumer profiles, etc.) networks assets. 


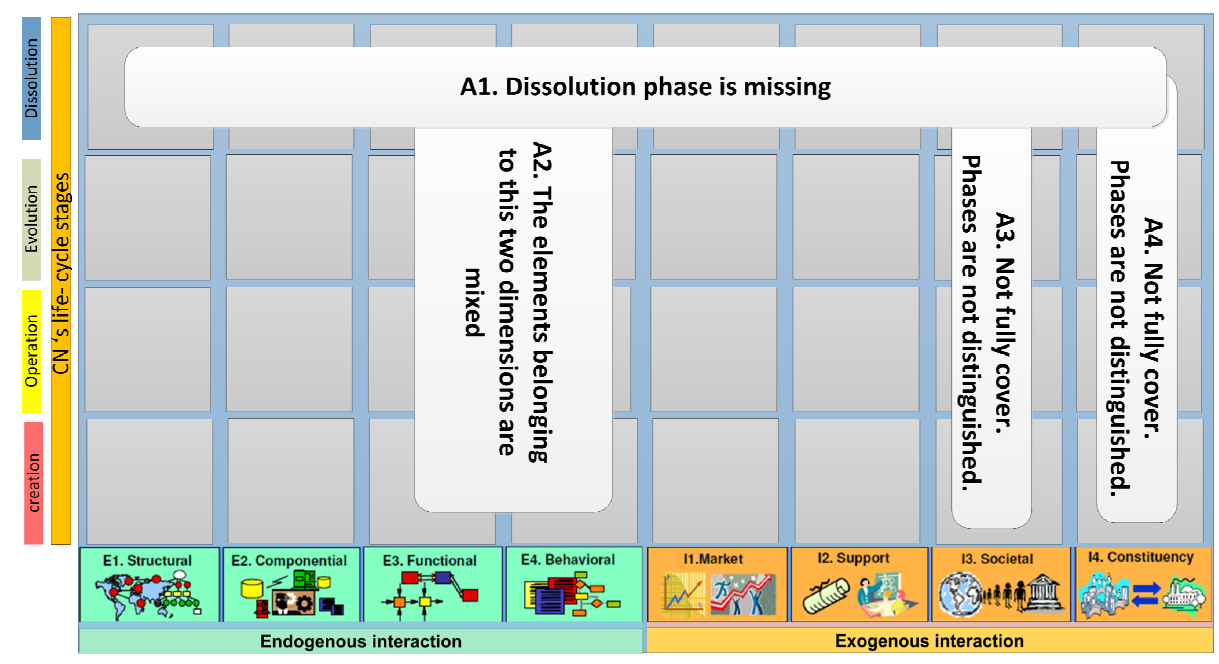

Fig. 3. PROVE local network gaps

A2. The use of ARCON allowed to make a clear distinction between executable operations and governance rules that drive PROVE's local network behavior. In fact, based on the information collected during this study we realized that members (Promoters, Facilitators and Farmers) were unaware of the difference between operation and governance rules. Furthermore, during the documentation analysis, we realized that the description of governance rules were mixed with the description of the work flows.

A3. The use of ARCON allowed concluding that the iteration between the network and society is not well defined for each life-cycle phase. In fact, based on the information collected during this study we realized that it is just possible to have a broad description of the relationships between the network and the local community. Several important items to characterize this issue are missing, such as: (i) types of relationships with external actors; (ii) evolution of relationships over the life-cycle; (iii) assessment of PROVE impact in society.

A4. The use of ARCON allowed realizing that the analysis of the potential iteration with new members is missing. In fact, based on the information collected during this study we concluded that promoters had not addressed some relevant issues of this dimension, such as: (i) definition of mechanisms to interact with local farmers in order to identify potential new members for the PROVE local network; (ii) identification of the various transactions types with public institutions over the lifecycle phases.

\section{Conclusions}

The globalization created an increasingly turbulent and competitive environment for agri-food sector. In this dynamic environment, farmers cannot afford to resist the 
market change and should abandon the beliefs and ingrained methods of work. As never before, today's farmers must develop new methods and competences to competing in a global market. However, to improve the sustainability of this management approach, structured models and methods should be applied. The use of a reference modelling framework in order to support the representation of the complexity of an alternative agri-food network can be an advantage. In this work, ARCON was used in order to represent in a systematic way the PROVE farmers' network. From the application of ARCON, a set of relevant issues about the PROVE network were identified, such as: (i) Dissolution phase was not specified, by the PROVE managers; (ii) There is not a clear distinction between executable operations and governance principles; (iii) Some relevant interactions are not clearly specified (e.g. between PROVE and society; and between PROVE and new members).

This case study illustrated the benefits of applying a reference modelling framework to specify and analyse this kind of collaborative networks. Nevertheless, in order to enable the use of the ARCON framework by end-users, and in this way promoting the use of formal methods in collaborative network management, it is important to develop a full practical software tool. Such software tool should aim to support the process of capturing the elements required to fill in the ARCON cells, and to provide reasoning mechanisms to analyze the obtained models.

Acknowledgments. This work was supported in part by the FCT-MCTES "Fundação para a Ciência e Tecnologia" (CTS multiannual funding) through the PIDDAC Program funds.

\section{References}

1. Abreu, A., Camarinha-Matos, L.M.: Understanding Social Capital in Collaborative Networks. In: Ortiz, Á., Franco, R.D., Gasquet, P.G. (eds.) BASYS 2010. IFIP AICT, vol. 322, pp. 109-118. Springer, Heidelberg (2010)

2. Abreu, A., Macedo, P., et al.: Towards a methodology to measure the alignment of value systems in collaborative networks. In: Azevedo, A. (ed.) Innovation in Manufacturing Network, vol. 266, pp. 37-46. Springer, Boston (2008)

3. Afsarmanesh, H., Camarinha-Matos, L.: The ARCON modeling framework. Collaborative networks: Reference modeling, pp. 67-82 (2008)

4. Baldo, F., Rabelo, R.: For a methodology to implement virtual breeding environments: a case study in the mold and die sector in Brazil. Leveraging Knowledge for Innovation in Collaborative Networks, 197-206 (2009)

5. Beckett, R., Jones, M.: Active Ageing: Using an ARCON Framework to Study U3A (University of the Third Age) in Australia. Adaptation and Value Creating Collaborative Networks, 189-196

6. Bosona, T., Gebresenbet, G., et al.: Box-Scheme Based Delivery System of Locally Produced Organic Food: Evaluation of Logistics Performance. Journal of Service Science and Management 4(3), 357-367 (2011)

7. Botarelli, M., Taticchi, P., et al.: The Virtual Development Office framework for business Networks: a case study from the Umbrian packaging district. In: Pervasive Collaborative Networks, pp. 611-618 (2008) 
8. Feenstra, G.W.: Local food systems and sustainable communities. American Journal of Alternative Agriculture 12(01), 28-36 (1997)

9. Ferreira, J.J.P.: The workflow-enabled supply chain, the Civil Construction Enterprise case study. International Journal of Logistics Research and Applications: A Leading Journal of Supply Chain Management 4(3), 297-311 (2001)

10. Garita, C.: A Case Study of VO Education in Costa Rica. In: Camarinha-Matos, L. (ed.) Virtual Enterprises and Collaborative Networks. IFIP AICT, vol. 149, pp. 589-596. Springer, Boston (2004)

11. Higgins, V., Dibden, J., et al.: Building alternative agri-food networks: Certification, embeddedness and agri-environmental governance. Journal of Rural Studies 24(1), 15-27 (2008)

12. O'Hara, S.U., Stagl, S.: Global food markets and their local alternatives: a socio-ecological economic perspective. Population \& Environment 22(6), 533-554 (2001)

13. PROVE. PROVE web site (2012), http: / /www . prove.com.pt/english (retrieved March 2012)

14. Volpentesta, A., Ammirato, S.: Networking agrifood SMEs and consumer groups in local agribusiness. Pervasive Collaborative Networks, 33-40 (2008)

15. Volpentesta, A.P., Ammirato, S.: A Collaborative Network Model for Agrifood Transactions on Regional Base. Organizational, Business, and Technological Aspects of the Knowledge Society 112, 319-325 (2010) 